\title{
Jerry's Map
}

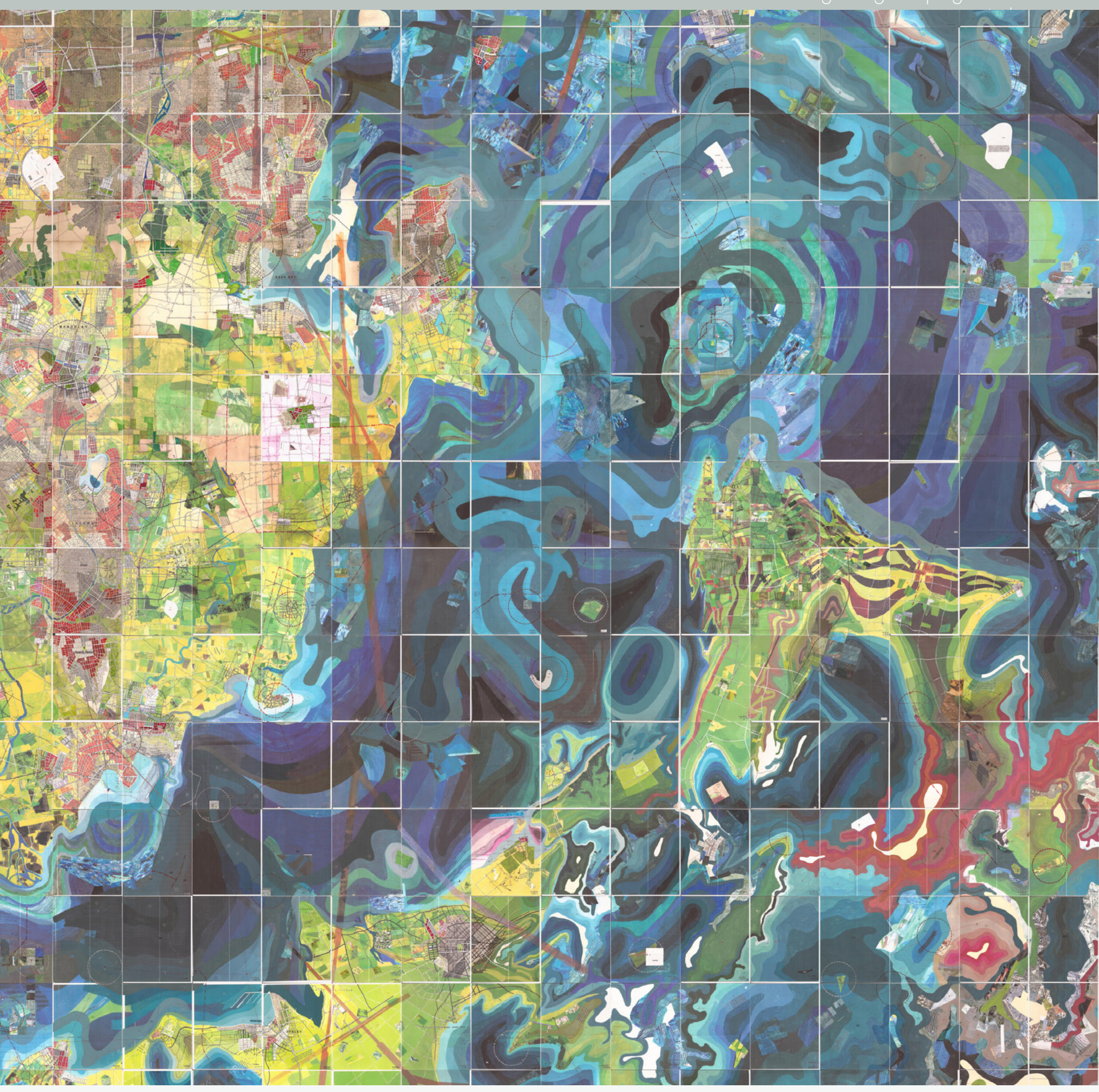

(c) $190 \begin{aligned} & 0 \text { by the author(s). This work is licensed under the Creative Commons Attribution-NonCommercial-NoDerivatives } \\ & 4.0 \text { International License. To view a copy of this license, visit http://creativecommons.org/licenses/by-nc-nd/4.0/. }\end{aligned}$ 
IN THE SUMMER of 1963, between my third and fourth years of college, I had a job at the Hoover Ball Bearing Company in Ann Arbor, MI. I rode my bike back and forth the four and a half miles to work where I monitored the production of bearings from a room mounted with mechanical counters linked to the machines on the factory floor. When a machine had completed its run it was my job to page the foreman and let him know. In my idle hours I started drawing a map of an imaginary place.

Now, more than fifty years later I am still working on that map. What began on a single sheet of paper has expanded to over 3,200 eight by ten inch panels which, when combined, measure nearly 50 by 50 feet. The map in its entirety was displayed at MASSMoCA in 2012, and at Summerhall in Edinburgh, Scotland this past year. It is scheduled to be shown at the Palais de Tokyo in Paris early in 2015.

The map itself is arranged by row, and sits in stacks on the shelves of my studio in the countryside of northern Michigan. The materials used to create the map today are reused items such as an old cereal boxes, newspapers, photographs, printed documents, and magazine clippings. Acrylic paint, marker, ink, and colored pencils are utilized to bring the map to life. It grows in size, and each panel evolves over time. Each successive generation begins as a
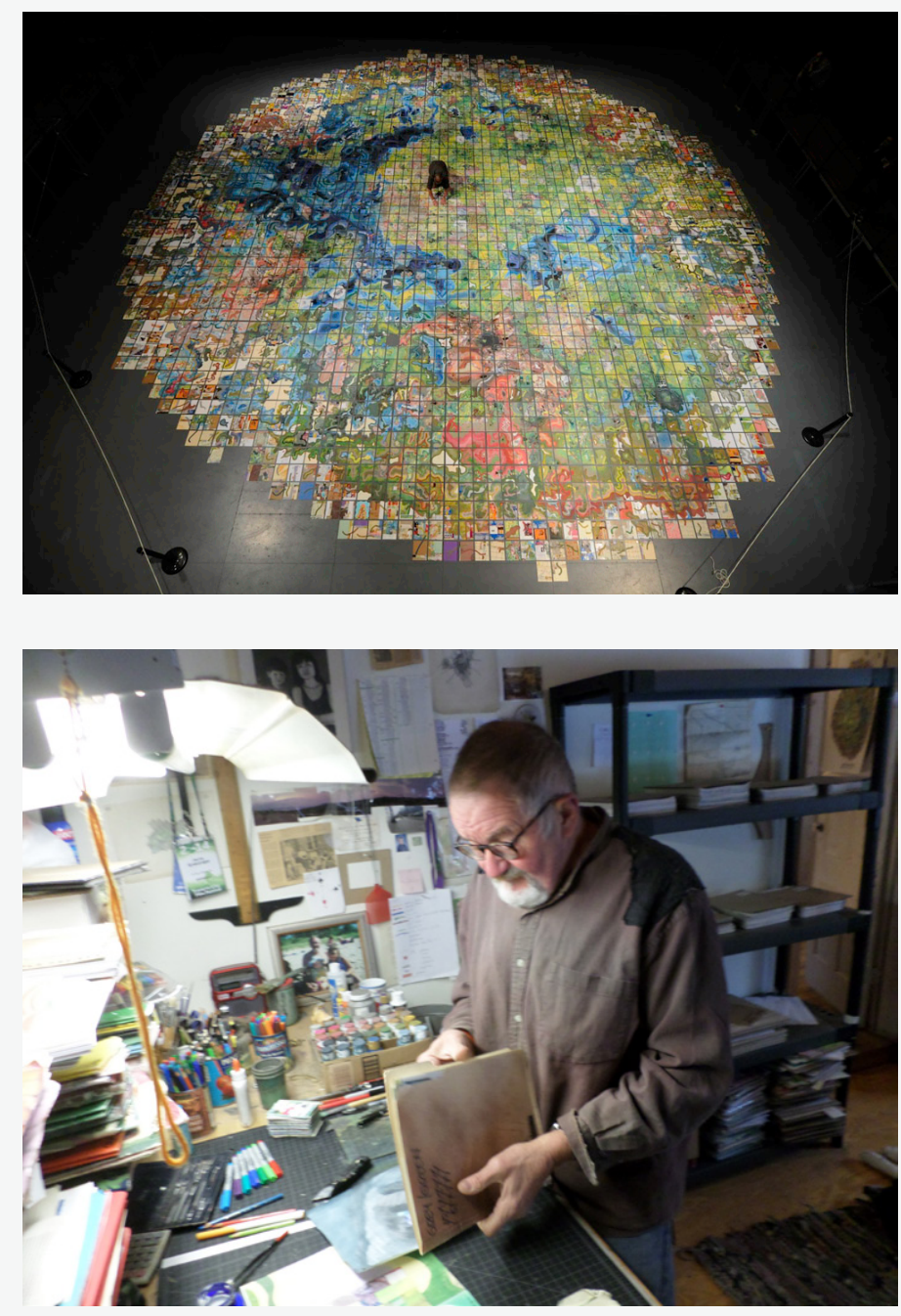

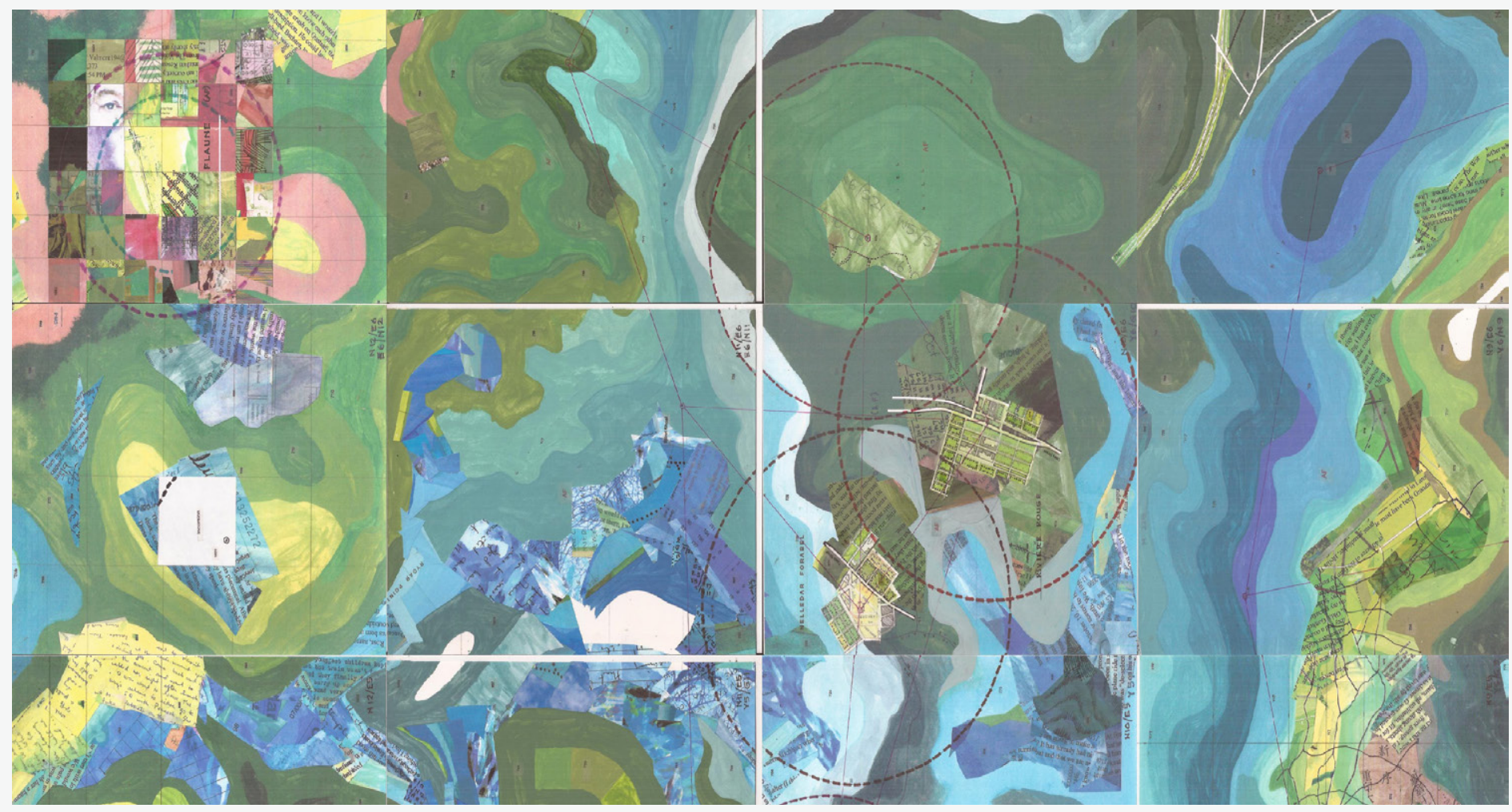




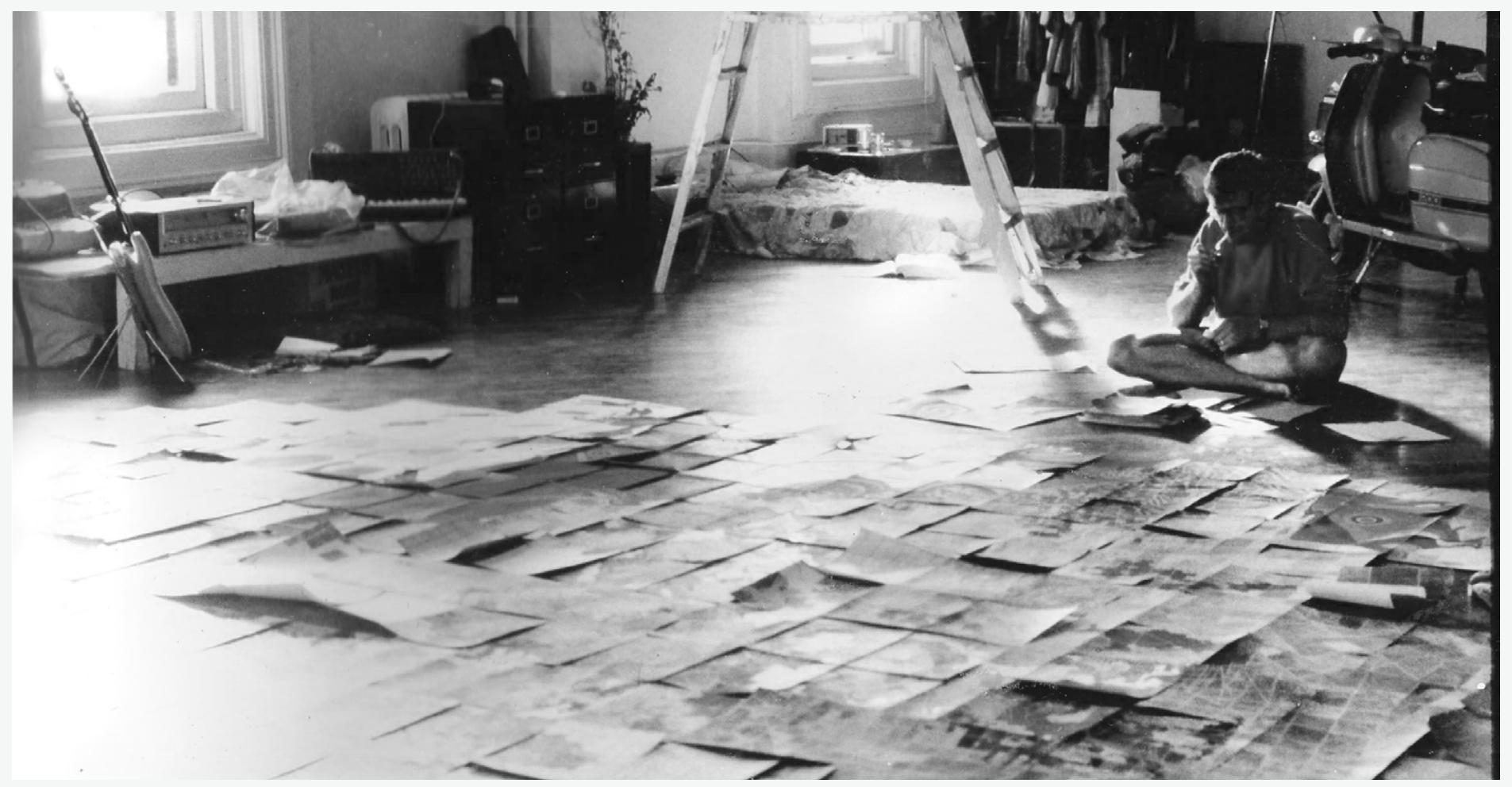

copy made by an inkjet printer, which is then manipulated further.

A deck of modified playing cards holds an elaborate set of rules, which I draw upon for every modification of the map. Some rules involve "housekeeping" tasks like updating the inventory of map panels or scanning sections. Others directly bear on the execution of the map: new void, new city, add a panel to the periphery, add a new color to the palette.

Jerry Gretzinger, born in Grand Rapids, Michigan in 1942, studied architecture and liberal arts at the Universities of Michigan and California. He joined the Peace Corps in 1964 and spent 2 years in Tunisia, later returning in 1968 as an architect with an archeological team cataloging the Roman mosaics there. He came back to the United States in 1973 and started a handbag design company in New York. In the early 1980s Jerry was joined by his wife Meg Staley in the design and manufacture of women's clothing. He retired to Maple City, Michigan in 2004.

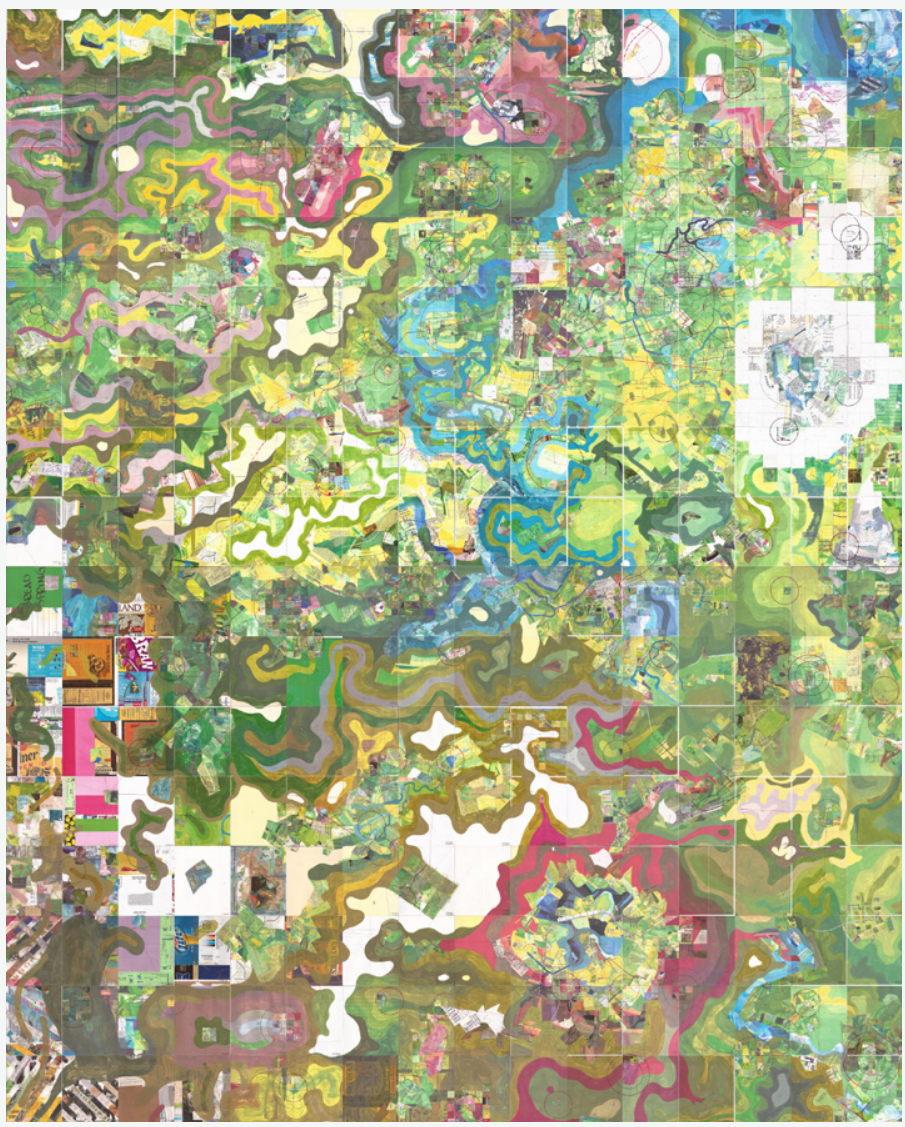

Visual Fields focuses on the appreciation of cartographic aesthetics and design, featuring examples of inspirational, beautiful, and intriguing work. Suggestions of works that will help enhance the appreciation and understanding of the cartographic arts are welcomed, and should be directed to the section editor, Laura McCormick: laura@xnrproductions.com. 